\title{
SYMPOSIUM
}

\section{Hippocampal volume and declarative memory function in combat-related PTSD}

\author{
STEVEN H. WOODWARD, ${ }^{1}$ DANNY G. KALOUPEK,,${ }^{2,3}$ LAURA J. GRANDE, ${ }^{4}$ \\ WENDY K. STEGMAN, ${ }^{5}$ CATHERINE J. KUTTER, ${ }^{6}$ LORAINE LESKIN,${ }^{7}$ REBECCA PRESTEL,${ }^{2}$ \\ MARIE SCHAER, ${ }^{8,9}$ ALLAN L. REISS, ${ }^{10}$ AND STEPHAN ELIEZ ${ }^{8}$ \\ ${ }^{1}$ Dissemination and Training Division, National Center for PTSD, VA Palo Alto Health Care System, Palo Alto, California \\ ${ }^{2}$ Behavioral Science Division, National Center for PTSD, VA New England Health Care System, Boston, Massachusetts \\ ${ }^{3}$ Division of Psychiatry, Boston University School of Medicine, Boston, Massachusetts \\ ${ }^{4}$ Psychology Service, VA New England Health Care System, Boston, Massachusetts \\ ${ }^{5}$ Earth Systems, Melbourne, Australia \\ ${ }^{6}$ Psychology Service, White River Junction Veterans Affairs Medical Center, White River Junction, Vermont \\ ${ }^{7}$ Psychology Service, VA Greater Los Angeles Health Care System, Los Angeles, California \\ ${ }^{8}$ Department of Psychiatry, University of Geneva, Geneva, Switzerland \\ ${ }^{9}$ Signal Processing Laboratory, Swiss Federal Institute of Technology, Lausanne, Switzerland \\ ${ }^{10}$ Department of Psychiatry and Behavioral Sciences, Stanford University Medical School, Stanford, California \\ (Received December 9, 2008; Final Revision May 11, 2009; Accepted May 11, 2009)
}

\begin{abstract}
The proposition that declarative memory deficits are systematically related to smaller hippocampal volume was tested in a relatively large sample $(n=95)$ of U.S. military veterans with and without combat-related posttraumatic stress disorder. This correlative analysis was extended by including multiple measures of verbal and visual declarative memory and multiple memory-relevant regional brain volumes that had been shown to exhibit main effects of PTSD in prior work. Small-to-moderate effects were observed on verbal declarative memory in line with a recent meta-analysis; nevertheless, little or no evidence of systematic linear covariation between memory measures and brain volumes was observed. (JINS, 2009, 15, 830-839.)
\end{abstract}

Keywords: PTSD, Memory, Cognition, Hippocampus, Neocortex, Magnetic resonance imaging

\section{INTRODUCTION}

The idea that the hippocampus contributes to declarative memory is a marquee finding of human neuropsychology; thus, it is natural to hypothesize that if PTSD patients have smaller hippocampi, and impaired declarative memory, then the two must be related. After all, a very strong confirmatory example is supplied by senile dementia of the Alzheimer's type (SDAT). Since the 1990s, numerous studies have reported significant correlations between hippocampal volume and declarative memory performances in SDAT (Laakso et al., 1995; Soininen et al., 1994) and also in minimally impaired elderly people (Convit et al., 1995; Zimmerman et al., 2008). Even a strongly disconfirmatory study, such as that of

Correspondence and reprint requests to: Steven H. Woodward, Ph.D., Dissemination and Training Division, National Center for PTSD, Mail Code 334 PTSD, VA Palo Alto HCS, 3801 Miranda Avenue, Palo Alto, CA 94304. E-mail: steve.woodward@va.gov
Marquis, which failed to find hippocampal volume and paragraph memory correlation in 108 older adults, many of whom progressed to dementia (Marquis et al., 2002), cannot dent our faith in the underlying relationship. The role of the hippocampus in memory, the histopathogically confirmed degeneration of that structure, combined with profound memory loss in SDAT, together constitute an unchallengeable framework. But unlike in SDAT, the memory impairments of PTSD are not profound. This is evidenced not only by the Brewin meta-analysis that found only a modest effect size for verbal memory (Brewin, Kleiner, Vasterling, \& Field, 2007). Memory loss is not among the diagnostic criteria for PTSD (the C3 symptom is specific to the circumstances of trauma.), is generally absent from self-report psychodiagnostics in this field, and is rarely, if ever, a focus of treatment. At the same time, hippocampal functionality has additional facets of potential relevance to PTSD. These include spatial/contextual processing (Bilkey, 2007; Fortin 
et al., 2008; Lang et al., 2009) and perhaps subservient to these, configural cue processing (Gilbertson et al., 2007). There is a danger that such alternative avenues for understanding the hippocampus in PTSD could be under-researched to the extent that a declarative memory framework is overvalued.

This article asks whether the framework that has been so successful in understanding SDAT should be applied to PTSD. In our view, strong tests of that framework are predicated on the presence of main effects of a PTSD diagnosis on both hippocampal structure and declarative memory performance. Employing these requirements, we have reviewed studies in the Karl meta-analysis of hippocampal findings in PTSD (Karl et al., 2006) and five studies published since then (Bonne et al., 2008; Bossini et al., 2008; Pavic et al., 2007; Tischler et al., 2006; Yehuda et al., 2007). Among those 26 studies, 16 reported a smaller hippocampus in PTSD in at least one hemisphere. Of those 16, 10 tested memory, but in one case, this was a test of implicit memory (Shin et al., 2004). Of the 9 studies testing declarative memory, 2 did not report whether group differences were found, and only 4 reported significantly worse memory in PTSD. Hence, notwithstanding the power of the SDAT example, a strong test of its applicability to PTSD rests on only four studies (Bremner et al., 1995, 1997; Nakano et al., 2002; Vythilingam et al., 2005). Of those four, two reported the expected correlations (Bremner et al., 1995; Vythilingam et al., 2005), and two did not, a chance rate. Among studies that have reported significant PTSD effects on hippocampal volume or declarative memory (but not both) and also tested structural-functional correlations, one reported positive findings (Tischler et al., 2006; Yehuda et al., 2007; these publications report on the same sample) and two had negative findings (Gurvits et al., 1996; Stein, Koverola, Hanna, Torchia, \& McClarty, 1997). Two additional studies that gathered data relevant to these correlations did not report them (Bremner et al., 2003; Pederson et al., 2004).

It could be argued that prior studies in this area have suffered from limited statistical power. The current study employed a sample of 95, two to three times larger than prior samples. As will be described later, and perhaps in part as a result of its greater power, this study met our criteria for a strong test in which both hippocampal volume and selected memory variables exhibited effects of PTSD (cf. Woodward, Kaloupek, Streeter, Kimble et al., 2006a). While the effects of a social stressor on declarative memory performances did not demonstrate effects of PTSD, we examined whether individual pre-/post-stress difference scores were related to hippocampal volumes (cf. McEwen \& Magarinos, 1997). We also had the opportunity of incorporating in the analyses other regional brain volumes arguably relevant to memory task performance, parahippocampal cortical volume and total cortical volume, that have been observed to differ over the PTSD-positive and PTSD-negative groups (cf. Woodward, Schaer, Kaloupek, Cediel, \& Eliez, in press).

\section{METHODS}

\section{Screening and Psychiatric Assessment}

Participants provided written informed consent in accordance with the procedures of the Institutional Review Boards of Stanford University Medical School/VA Palo Alto HCS or Boston VA Medical Center and the McLean Hospital. Recruitment and screening of this sample at two sites was described in detail in a prior publication (Woodward, et al., 2006a; Woodward, Kaloupek, Streeter, Martinez et al., 2006b). Two subjects were excluded because of an imaging artifact that disrupted cortical sheet extraction, and two because of the loss of testing data. PTSD was diagnosed and its severity estimated using the Clinician-Administered PTSD Scale (CAPS, Blake et al., 1997). Assessments of mood status, psychosis and associated symptoms, alcohol and substance use disorders, and anxiety disorders were performed using the Structured Clinical Interview for the DSM-IV (First, Spitzer, Gibbon, \& Williams, 1995). Also administered were the Combat Exposure Scale (Keane et al., 1989), Life Events Checklist (LEC, Blake et al., 2000), Mississippi Scale for Combat-related PTSD (MISS, Keane, Caddell, \& Taylor, 1988), Beck Depression Inventory (BDI, Beck, Ward, Mendelson, Mock, \& Erbaugh, 1961), and Michigan Alcohol Screening Test - Short Form (SMAST, Selzer, 1971). Eighty-four subjects also underwent a structured interview to determine whether LEC-elicited trauma endorsements fulfilled PTSD Criterion A1 and A2 and when they occurred.

\section{Participants}

All 95 final participants were combat veterans of the Vietnam or Persian Gulf wars. All were free of acute medical disease, current substance abuse/dependence (abstinent more than six months), central nervous system (CNS) disease, and psychosis. PTSD-positive (PTSD+) participants met criteria as a result of experiencing one or more military traumas, but some also experienced civilian traumas before or after their military service. PTSD-negative (PTSD-) participants had never met criteria for PTSD as a result of military or civilian trauma. Table 1 presents selected subsample means. Noteworthy among them, the combat exposure scale (CES), and CAPS score means indicate that the PTSD+ subsample was heavily combat-exposed and severely symptomatic. They were also severely dysphoric, as indexed by mean BDI scores greater than 20. Of the PTSD+ participants, $75 \%$ also met criteria for current major depressive disorder (MDD) versus 4\% of PTSD- participants, while for lifetime MDD the corresponding rates were $85 \%$ and $22 \%$. Among subjects with histories of alcohol abuse/dependence $(\mathrm{ETOH})$, those with PTSD had begun drinking, on average, 4.7 years earlier than those without PTSD (20.7 vs. 25.4 years, respectively). Participants were maintained on their psychotropic medications. In line with their symptomatic status, $69 \%$ of the PTSD+ participants were taking 
Table 1. Study matrix coding the presence/absence of the features of a "strong test" of the proposition that hippocampal volume and declarative memory capacity are directly correlated in PTSD as they are in SDAT

\begin{tabular}{|c|c|c|c|c|}
\hline & $\begin{array}{c}\text { Smaller } \\
\text { hippocampus }\end{array}$ & $\begin{array}{l}\text { Relative declarative } \\
\text { memory impairment }\end{array}$ & $\begin{array}{l}\text { Hippocampal volume } \\
\text { and declarative } \\
\text { memory correlated }\end{array}$ & Notes \\
\hline Bremner 1995 & 1 & 1 & 1 & \\
\hline Gurvits 1996 & 1 & 0 & 0 & \\
\hline Bremner 1997 & 1 & 1 & 0 & \\
\hline Stein 1997 & 1 & NR & 0 & $\begin{array}{l}\text { memory results } \\
\text { reported later }\end{array}$ \\
\hline De Bellis 1999 & 0 & & & \\
\hline Bonne 2001 & 0 & & & \\
\hline De Bellis 2001 & 0 & & & \\
\hline Schuff 2001 & 0 & & & \\
\hline De Bellis 2002 & 0 & & & \\
\hline Fenemma-Notestine 2002 & 0 & & & \\
\hline Gilbertson 2002 & 1 & & & \\
\hline Lindauer 2002 & 1 & & & \\
\hline Nakano 2002 & 1 & 1 & 0 & \\
\hline Villarreal 2002 & 1 & & & \\
\hline Bremner 2003 & 1 & NR & & \\
\hline Hedges 2003 & 1 & & & \\
\hline Pederson 2004 & 0 & 0 & NR & \\
\hline Shin 2004 & 1 & 0 & & $\begin{array}{l}\text { tested implicit } \\
\text { memory }\end{array}$ \\
\hline Wignal 2004 & 1 & & & \\
\hline Winter 2004 & 1 & & & \\
\hline Vythilingham 2005 & 1 & 1 & 1 & \\
\hline Tischler 2006/Yehuda 2007 & 0 & 1 & 1 & \\
\hline Pavic 2007 & 1 & & & \\
\hline Bonne 2008 & 1 & & & \\
\hline Bossini 2008 & 1 & & & \\
\hline Weniger 2008 & 1 & 1 & 1 & trauma-related DID \\
\hline
\end{tabular}

Note. Studies are those meta-analyzed in Karl et al (2006) plus five relevant studies published later. A " 1 " or a " 0 " indicates the proposition heading the column was tested, a " 1 " indicates a positive finding, a " 0 ", indicates a negative finding. NR indicates that the data were reportedly available for a test, but the test was not performed or was not reported. Weniger et al (2008) is included for completeness, but considered trauma-related dissociative identity disorder not PTSD.

psychotropic medications versus $11 \%$ of PTSD- participants. Forty-four percent of the PTSD+ participants, $44 \%$ were taking selective serotonin reuptake inhibitors versus only $4 \%$ of PTSD- participants. Twenty-one percent of PTSD+ participants were taking anticonvulsant $/$ moodstabilizing medications, whereas no PTSD- participants were taking medications from this class.

\section{Procedures}

Participants arrived at the laboratory at approximately 0800. Structured psychodiagnostic interviews, self-report psychometrics, and baseline memory and cognitive testing required approximately four hours including breaks. After lunch, participants were prepared for psychophysiological recording (electroencephalogram, electro-oculogram, facial electromyogram, electrocardiogram, abdominal respiration, electrodermal activity). They then underwent two administrations of the Trier Social Stress Test (TSST, Kirschbaum, Wolf, May, Wippich, \& Hellhammer, 1996) separated by a 40-minute rest period. After each TSST, declarative memory was assessed and a brief "oddball" eventrelated potential protocol was administered. After the completion of laboratory testing, participants were transported to the magnetic resonance imaging (MRI) laboratories for neuroimaging.

Verbal declarative memory was assessed at baseline using the Logical Memory (LM) subtest of the Wechsler Memory Scale-III (WMS-III, Wechsler, 1997) and the Hopkins Verbal Learning Test (HVLT, Brandt, 1991). Visual declarative memory was assessed using the Rey-Osterrieth Complex Figure Test (ROCFT) (Osterrieth, 1944; Rey, 1941; Spreen \& Strauss, 1991) and the Rey Visual Design Learning Test (RVDLT, see Spreen \& Strauss, 1991). The baseline assessment also included administrations of the Vocabulary subtest (VOCAB) and Digit Symbol Substitution (DSS) subtest of the Wechsler Adult Intelligence Test-III (WAIS-III , Psychological Corporation, 1997). After each administration of the TSST, the HVLT and the RVDLT were repeated using equivalent forms. 


\section{Image Acquisition and Processing}

Magnetic resonance (MR) images of subjects' brains were acquired with 1.5T GE Signa II systems located near each study site (Diagnostic Radiology Center of Veterans Affairs, Palo Alto Health Care System and the Brain Imaging Center of McLean Hospital, Belmont, MA). Coronal images were acquired with a 3D spailed-gradient recalled (SPGR) volumetric pulse sequence $(\mathrm{TR}=35 \mathrm{~ms}, \mathrm{TE}=6 \mathrm{~ms}$, flip angle $=$ $45^{\circ}, \mathrm{NEX}=1$, matrix size $=256 \times 192$, field of view $=24 \mathrm{~cm}^{2}$, slice thickness $=1.5-1.7 \mathrm{~mm}$, slices $=124$.)

This article considers brain structural indices obtained through two independent MR image analysis methods. Volumes of the hippocampus were obtained using manual tracing in accordance with the methods of the Stanford Psychiatry Neuroimaging Laboratory (Kates, Abrams, Kaufmann, Breiter, \& Reiss, 1997; Reiss et al., 1998; Woodward, et al., 2006a). Image optimizations promoted accurate and reliable delineation of the hippocampal cross-sections on each slice. The anterior limit of the hippocampus was defined by the hippocampal sulcus or alveus, and the posterior limit by the fusion of the fornix with the splenium. Manual delineation was performed by a single rater (W.K.S.), trained to criterion within the Stanford Psychiatry Neuroimaging Laboratory, and blinded to participant identity and diagnosis. This processing protocol also produced various lobar tissue volume estimates via projection to and parcellation in Talairach space (Talairach \& Tournoux, 1988). We have observed trends for these macro-volumes to be smaller in the PSTD+ participants in this study, but these trends have not achieved significance despite the relatively large size of this sample (Woodward et al., 2007; Woodward, et al., 2006a). Hence, this article employed total cerebral tissue volume only to normalize hippocampal volume across persons differing in gross body size. Cross-site reliabilities were established by imaging seven study staff in both magnets and recalculating all volumes in a blinded fashion. Cross-site reliabilities of hippocampal and total cerebral tissue volumes (gray + white) exceeded $r_{\text {ICC }}=0.90$.

Estimates of the volumes of parahippocampal and total cortices were obtained using FreeSurfer (version 4.0.1; Martinos Center for Biomedical Imaging, Massachusetts General Hospital, Boston, MA). This automated approach extracts an accurate yet geometrically tractable model of the 2-dimensional cortical sheet (for details, see Dale Fischl, \& Sereno, 1999; Fischl \& Dale, 2000; Fischl, Sereno, \& Dale, 1999). One key feature of FreeSurfer is its exploitation of the fact that the gray-white boundary is planar at short distances, information that improves gray/white segmentation and renders it relatively robust to MR system variations (Han et al., 2006). Secondly, cross-subject registration is performed by projecting cortical surface models onto "inflated" or spherical representations, and cross-aligning using the large-scale features of the cortex, such as the central sulcus (Fischl, Sereno, \& Dale, 1999; Fischl, Sereno, Tootell, \& Dale, 1999). This feature of the method reduces cortical registration error in comparison to volume-keyed approaches, such as voxel-based morphometry. Cortical thickness is then computed as the distance between the inner and the outer cortical surfaces (Fischl \& Dale, 2000). At this juncture, the Desikan et al. (Desikan et al., 2006; Fischl et al., 2004) parcellation was applied to delineate cortical regions a priori, after which the thicknesses and areas of the separate parcels were calculated. We focused here on two memory-relevant cortical regions, which prior analyses showed to be smaller in volume (the product of area and thickness) in association with PTSD in this sample, the parahippocampal cortex and the total cerebral cortex (see below, Woodward et al., in press).

\section{RESULTS}

\section{Cognition}

WAIS VOCAB and DSS were compared over groups using analyses of covariance (ANCOVAs) covarying for age. VOCAB exhibited an interaction between PTSD and ETOH $\left(\mathrm{F}(1,90)=8.44, p<.01\right.$, partial $\left.\eta^{2}=0.086\right)$ related to the fact that the effect of PTSD (lower scores associated with PTSD) was only significant in participants with lifetime ETOH $(\mathrm{ETOH}+: F(1,39)=18.7, p<0.001$; ETOH-: $F(1,50)=$ $0.42, n s)$. VOCAB also exhibited a main effect of PTSD, $F(1,92)=14.2, p<.001$, partial $\eta^{2}=0.136$. The effect of ETOH was also significant, $F(1,90)=5.07, n s$, partial $\eta^{2}=$ 0.053 , with lower VOCAB performance observed in participants with histories of ETOH. PTSD was strongly associated with lower DSS scores, $F(1,92)=33.0, p<.001$, partial $\eta^{2}=$ 0.268 ; however, unlike VOCAB, DSS exhibited no effect of ETOH and no interaction of PTSD and ETOH $\left(F_{\mathrm{s}}<1\right)$. The size of the PTSD effect on DSS was similar in $\mathrm{ETOH}+$ and ETOH- subgroups (partial $\eta^{2}=0.275$ vs. 0.285).

\section{Regional Brain Volumes}

The reader is directed to our prior publications for detailed presentations of the differences we have found between PTSD+ and PTSD- participants in this sample. In those studies, hippocampal tissue (gray + white) volume, parahippocampal cortical volume, and total cerebral cortical volume have all been shown to be smaller in the PTSD+ relative to the PTSD- participants (Woodward, et al., 2006a; Woodward et al., in press).

\section{Memory}

Table 2 presents means and standard deviations of the memory variables considered in this study. Baseline performance on the LM subtest of the WMS-III was analyzed for associations with PTSD and lifetime alcoholism (ETOH) using repeated-measures ANCOVA covarying for age and VOCAB. A within-subjects factor of recall trial contrasted immediate versus delayed recall. Participants with PTSD exhibited mildly reduced LM performance relative to those without PTSD, $F(1,89)=4.27, p<.05$, partial $\eta^{2}=0.046$. Although subjects' performances declined nominally at recall, the 
Table 2. Raw means and standard deviations of selected sample description variables

\begin{tabular}{|c|c|c|c|c|c|c|c|c|c|c|c|}
\hline \multirow[b]{4}{*}{$\mathrm{N}$} & \multicolumn{4}{|c|}{ PTSD+ } & \multicolumn{4}{|c|}{ PTSD- } & & & \\
\hline & \multirow{2}{*}{\multicolumn{2}{|c|}{$\frac{\text { ETOH+ }}{23}$}} & \multirow{2}{*}{\multicolumn{2}{|c|}{$\frac{\text { ETOH- }}{25}$}} & \multirow{2}{*}{\multicolumn{2}{|c|}{$\begin{array}{c}\text { ETOH+ } \\
19\end{array}$}} & \multirow{2}{*}{\multicolumn{2}{|c|}{$\frac{\mathrm{ETOH}-}{28}$}} & \multirow{2}{*}{\multicolumn{3}{|c|}{ partial $\eta^{2}$}} \\
\hline & & & & & & & & & & & \\
\hline & M & SD & M & SD & M & SD & M & SD & PTSD & ETOH & Interactions \\
\hline AGE & 50.2 & 7.3 & 48.3 & 9.0 & 47.1 & 11.1 & 45.9 & 9.5 & & & \\
\hline WAIS VOCAB & 42.7 & 11.2 & 52.2 & 9.5 & 55.0 & 7.2 & 53.5 & 8.1 & 0.136 & 0.053 & $\begin{array}{c}\text { PTSD } \times \\
\text { ETOH: } \\
\text { 0.086 }\end{array}$ \\
\hline WAIS DSS & 57.8 & 14.0 & 57.1 & 16.4 & 74.2 & 11.2 & 75.9 & 14.8 & 0.268 & & \\
\hline CES & 26.9 & 12.3 & 27.5 & 11.1 & 18.1 & 8.6 & 16.2 & 11.9 & 0.170 & & \\
\hline CAPS-TS & 78.3 & 14.9 & 73.0 & 21.5 & 19.2 & 9.5 & 8.4 & 10.5 & 0.830 & & \\
\hline BDI & 24.9 & 7.7 & 22.2 & 9.1 & 5.3 & 3.5 & 3.8 & 3.9 & 0.683 & & \\
\hline SMAST & 6.6 & 3.8 & 1.2 & 1.2 & 2.5 & 3.4 & 0.2 & 0.4 & 0.211 & 0.380 & 0.092 \\
\hline Height & 70.3 & 2.3 & 69.8 & 3.1 & 70.0 & 3.0 & 69.7 & 3.3 & & & \\
\hline
\end{tabular}

Note. Effect sizes are supplied for statistically significant effects. Effect sizes on WAIS variables derived from ANCOVAs covarying age.

effect of recall trial did not approach significance $(F<1)$. Recall trial also did not interact with PTSD, ETOH, or their interaction. Similarly, neither ETOH, $F(1,89)=1.65, n s$, nor the PTSD $\times$ ETOH interaction $(F<1)$ influenced overall LM performance. Baseline performance on the ROCFT, analyzed in a similar fashion, exhibited the expected effect of trial [copy vs. recall: $F(1,90)=12.2, p<.001$ ], and a main effect of PTSD, $F\left(1,89=6.9, p<.01\right.$, partial $\eta^{2}=0.072$. There was no effect of ETOH and no interactions.

Performances on the HVLT and the RVDLT were analyzed using repeated-measures ANCOVAs, covarying for age and VOCAB. The within-subjects factor, session, had three levels contrasting baseline, post-TSST1, and postTSST2 administrations. Thus, the session factor incorporated the impact of the TSST on subsequent verbal memory and visual declarative memory performances. For both, total learning and percent retention were analyzed separately. HVLT total learning exhibited a modest effect of PTSD, $F(1$, $89)=5.89, p<.05$, partial $\eta^{2}=0.062$. There was no effect of ETOH, $F(1,89)=1.63, n s$, partial $\eta^{2}=0.018$, and no PTSD $\times$ ETOH interaction, $F(1,89)=0.731, n s$, partial $\eta^{2}=0.008$. The effect of session was not significant, Wilks' Lambda $=$ $0.974, F(2,88)=1.16, n s$. HVLT percent retention exhibited a significant interaction of PTSD, ETOH, and Session, Wilks' Lambda $=0.900, F(2,88)=4.89, p<.01$, partial $\eta^{2}=0.10$. Underlying this three-way interaction was a difference between PTSD+ and PTSD- subgroups as to the presence of an ETOH x Session interaction. This two-way interaction was significant only in PTSD+ participants, Wilks' Lambda $=0.842, F(2,43)=4.89, p<.01$, partial $\eta^{2}=0.158$, among whom HVLT percent retention diverged on the third (post-TSST2) trial as a function of ETOH. That is, for PTSD+/ETOH+ participants, HVLT retention dropped precipitously at post-TSST2 $(96 \%, 91 \%, 82 \%$, respectively), whereas for PTSD+/ETOH- participants, it improved relative to post-TSST1 $(91 \%, 87 \%, 94 \%$, respectively). There were no additional group effects or interactions influencing HVLT percent retention. RVDLT performances exhibited no significant main effects or interactions.

\section{Covariations Among Regional Brain Volumes and Memory Performances}

Table 3 presents zero-order correlations between the regional brain volumes and memory performances considered in this study. Also included are HVLT and RVDLT total learning pre-/post-stress change scores. All variables exhibited normal distributions, supporting the use of parametric Pearson product-moment correlations. Review of bivariate plots confirmed that no correlation was artifactually amplified or attenuated by outliers or range restriction. By far, the strongest

Table 3. Raw means and standard deviations of memory performance variables

\begin{tabular}{lccccc}
\hline \hline & \multicolumn{2}{c}{ PTSD } & & \multicolumn{2}{c}{ PTSD- } \\
\cline { 2 - 3 } \cline { 5 - 6 } & M & SD & & M & SD \\
\hline LM total learning & 27.9 & 5.7 & & 32.8 & 5.5 \\
LM delayed recall & 23.6 & 7.3 & & 27.7 & 7.2 \\
HVLT total learning & 26.3 & 4.1 & & 28.6 & 3.7 \\
HVLT retention & 0.92 & 0.12 & & 0.93 & 0.13 \\
ROCFT copy & 60 & 7.3 & & 63.4 & 7.5 \\
ROCFT recall & 30.6 & 13.3 & & 36.9 & 10.9 \\
RVDLT total learning & 9.4 & 2.9 & & 10.6 & 2.7 \\
RVDLT retention & 0.89 & 0.29 & & 0.97 & 0.13 \\
HVLT change & 0.6 & 3.9 & & -0.2 & 4.1 \\
$\quad$ trial 2 - trial 1) & & & & \\
RVDLT change & 0.3 & 3.8 & -0.3 & 3.7 \\
$\quad$ (trial 2 - trial 1) & & & & \\
\hline \hline
\end{tabular}




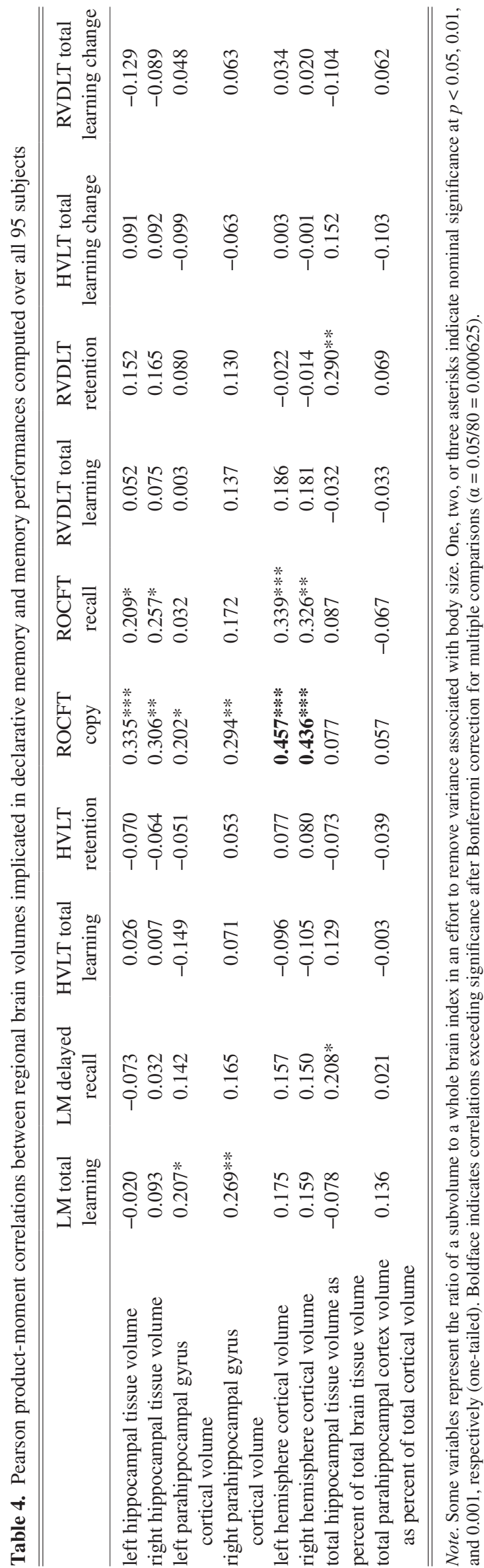

relationships, and the only ones exceeding a conservative level of statistical significance in light of the number of comparisons $(\alpha=.05 / 80=0.000625)$, involved ROCFT copy performance. Positive correlations $(r \mathrm{~s}=0.284-0.441, d f \mathrm{~s}=93)$ were observed between this measure and all raw brain volumes. ROCFT recall scores exhibited a similar but weaker pattern of covariance $(r \mathrm{~s}=0.120-0.347, d f \mathrm{~s}=93)$. Neither ROCFT performance correlated with hippocampal or parahippocampal volumes expressed as a proportion of their embedding macrovolumes. In the whole sample, neither left nor right raw hippocampal tissue volumes correlated with any index of memory performance $(r s=0.120-0.347, d f \mathrm{~s}=93)$. Correlations between total hippocampal tissue volume and memory performances did not differ substantially over study sites (Palo Alto: $r \mathrm{~s}=-0.097-0.251$; Boston: $r \mathrm{~s}=-0.169$ 0.272). Total hippocampal tissue volume expressed as a proportion of total brain tissue volume was nominally positively correlated with LM delayed recall (but not total learning) and RVDLT retention; however, both correlations were insignificant after partialing shared variance with VOCAB $(r \mathrm{~s}=-0.083$ and 0.138 , respectively). Left and right parahippocampal gyrus volumes were both nominally positively correlated with LM total learning scores (but not retention), and remained so after partialing out shared variance with $\operatorname{VOCAB}(r s=0.208$ and 0.209 , respectively, $p s<.05$ ).

Because a history of ETOH could have moderated the relationship between brain structure and memory (Harris et al., 2008), these correlations were recalculated in the ETOH+ and ETOH- subjects, separately. Within both groups, a cluster of nominally significant positive correlations were again observed to involve ROCFT copy and recall measures. Among ETOH+ participants, a second cluster of four positive correlations were observed to associate total cortical volume (left and right) with LM performance (total learning and delayed recall); however, none of these remained even nominally significant after partialing out shared variance with VOCAB. In the end, in neither subgroup analysis did a single correlation exceed a level of statistical significance corrected for multiple comparisons $(\alpha=.05 / 80=0.000625)$.

An analysis of the impacts of depression and/or medication status on cognitive performances is beyond the scope of this article, as both are highly confounded with PTSD in this sample. The sample does provide a limited opportunity to test medication effects within the PTSD group. DSS performance did not differ over PTSD+ subjects who were and were not taking GABAergic medications, 56.1 vs. 57.8, $t(46)=0.311$, $n s$. Similarly, neither LM total learning nor HVLT total learning exhibited differences between subgroups of PTSD+ subjects who were versus were not taking (1) any psychotropic drug, (2) an SSRI, or (3) a GABAergic medication.

\section{DISCUSSION}

Participants in this study exhibited a pattern of small to moderate effects of PTSD on memory for nonemotional materials with no effect of delay. This pattern is very similar to that observed by Brewin et al. in their meta-analysis of memory 
studies in PTSD (Brewin et al., 2007). As noted, this same sample had previously demonstrated effects of PTSD on hippocampal volume in line with most studies in this area (Karl et al., 2006; Woodward, et al., 2006a). This study employed a sample more than twice as large as earlier studies reporting correlations between hippocampal volume and memory performance (Bremner et al., 1995; Vythilingam et al., 2005). It used similar or identical memory measures. In addition, a widened net was cast by assessing the volumes of additional brain structures such as parahippocampal and total cortex that were both smaller in the PTSD+ subsample and memory-relevant (cf. Wais, 2008). We also examined correlations between memory and regional brain subvolumes expressed as percentages of the embedding whole-brain or whole-cortex volumes in an effort to control for differences in body size, and separately examined alcoholic and nonalcoholic subsamples. Unexpectedly strong relationships were observed between ROCFT copy performances and most brain volumes considered. These relationships were apparent in participants with and without histories of alcoholism. We are not aware of prior studies demonstrating strong structural-functional relationships associating figure copying and regional brain volumes; nevertheless, these were the only correlations with magnitudes comfortably exceeding chance levels, given the number of tests performed. We have reported previously that verbal IQ, as estimated by VOCAB, was moderately correlated with total cortical volume in this sample (cf. Andreasen et al., 1993; Woodward et al., in press). Correlations involving the verbal memory, such as LM performance, though in biologically plausible directions, were substantially smaller, and likely mediated in part by verbal intelligence. Relationships between hippocampal volume and stressor effects on memory were wholly absent. In summary, linear covariation between regional brain volumes and memory performances were given ample opportunity to emerge, but did not do so in a convincing fashion.

Although this appears to be a relatively strong negative result, it is clearly not definitive. As always, sampling error could have accounted for our failure to observe stronger relationships between hippocampal volume, other regional volumes, and memory performances. While the neuropathology and memory loss characteristic of SDAT provide a strong example, Sapolsky has noted that no clear links exist between stress-related cellular adaptations in the hippocampus and its gross volume (Sapolsky, 2000). Hippocampal cell loss in SDAT is relatively generalized (Simic, Kostovic, Winblad, \& Bogdanovic, 1997). In contrast, stress-related impacts on apical dendritic remodeling are specific to CA3, while those on neurogenesis are specific to the dentate gyrus (Gould \& Tanapat, 1999). These structures each comprise only a fraction of the hippocampal cross-section. If the impact of dentate atrophy on the volume of the hippocampus was proportional, and the dentate contributed $20 \%$ of the hippocampal cross-section, a halving of the dentate would be required to produce only a $20 \%$ decrease in the parent structure. It is also germane here that glucocorticoid-driven depletion of mitochondria (Coburn-Litvak et al., 2004) and synaptic numbers (Tata, Marciano, \& Anderson, 2006) have been observed in rat hippocampus in the absence of smaller volume.

These considerations may guide us back to the common finding that the declarative memory deficits of nonelderly persons with PTSD are relatively modest (Brewin et al., 2007; cf. Golier, Harvey, Legge, \& Yehuda, 2006; Yehuda, Golier, Tischler, Stavitsky, \& Harvey, 2005). In this study, by comparison, we observed an effect of PTSD on the WAIS DSS subtest more than twice as large as those on LM or HVLT. Samuelson also observed DSS performance (along with Letter-Number Sequencing and Digit Span) to exhibit strong effects of PTSD in the absence of significant effects on LM (Samuelson et al., 2006). The origins of these associations deserve further attention, and provide further support for casting a wide net in our efforts to document the neurocognitive deficits of PTSD. Findings from emotional Stroop tasks (McNally, 1998; Metzger, Orr, Lasko, McNally, \& Pitman, 1997; Vythilingam et al., 2007) suggest that functional cognitive impairments in PTSD may lie preferentially at the interface with fear- and other trauma-related affects; however, Stroop tasks test only word reading. Novel assessments of the cognition-affect interface could borrow from the PTSD literature methods for safely inducing mood states and cognitive sets harkening back to the conditions of traumatization. Although such procedures might pose challenges to face-to-face neuropsychological assessment, they may be compatible with computer-based assessments such as the Automated Neuropsychological Assessment Metrics (cf. Vasterling et al., 2006).

In conclusion, a review of the existing literature relating hippocampal volume to memory performance in PTSD, and an extended re-examination of that relationship in a larger sample, appear to be in agreement. The strong example of SDAT may not be heuristic in this disorder, and alternative perspectives on the function of the hippocampus and related structures may be more revealing.

\section{ACKNOWLEDGMENTS}

Major funding for this work was provided under a VA/DoD assistance agreement to Drs. Woodward and Kaloupek from the U.S. Army Medical Research and Materiel Command (DoD) administered through the Institute for Medical Research (VA). Special thanks are due to Stephen Grate and Lori Moll who facilitated the necessary arrangements at those institutions. Support was also provided by a National Institute on Alcohol Abuse and Alcoholism award (K23AA13149) and a VA Career Development Award to Dr. Streeter. Support for Dr. Eliez was provided by the Swiss National Fund for Research Career Development Award (32-63135-00 and PP00B-102864/1). The authors wish to thank the Research Services of the VA Palo Alto and VA Boston Healthcare Systems for their support. Important institutional and technical support was also provided by the following individuals: at the VA Palo Alto HCS, John E. Drace, Patricia Spezia, Carla Ambriz, and Gary E. Gold; at the VA Boston HCS, Chris C. Streeter, Kelly Teresi, Frederick Kanter, Steven Blank, Susan Proctor, and Erica Stone; at Stanford University, Thomas J. Brosnan, Anil Patwardhan, and Eric Schmitt; 
at McLean Hospital, Perry Renshaw, Blaise Frederick, Rosemond Villafuerte, Ann Smith, and Eileen Connolly; and at the Defense Manpower Database Command, Michael A. Dove. The authors are also grateful for the guidance provided by Kelvin O. Lim, Stephen E. Lindley, Craig Rosen, and H. Stefan Bracha. The neuropsychological assessment results and relations to neuroimaging have not been published either electronically or in print. No authors have conflicts of interest in relation to the findings published in this article.

\section{REFERENCES}

Andreasen, N., Flaum, M., Swayze, V.N., O’Leary, D., Alliger, R., Cohen, G., et al. (1993). Intelligence and brain structure in normal individuals. American Journal of Psychiatry, 150, 130-134.

Beck, A.T., Ward, C.H., Mendelson, M., Mock, J., \& Erbaugh, J. (1961). An inventory for measuring depression. Archives of General Psychiatry, 4, 561-571.

Bilkey, D.K. (2007). Space and context in the temporal cortex. Hippocampus, 17(9), 813-825.

Blake, D., Weathers, F., Nagy, L., Kaloupek, D., Klauminzer, G., Charney, D., et al. (2000). Clinician-Administered PTSD Scale (CAPS) instructional manual: National Center for PTSD.

Blake, D.D., Weathers, F.W., Nagy, L.M., Kaloupek, D.G., Charney, D.S., \& Keane, T.M. (1997). Clinician-Administered PTSD Scale for DSM-IV: Current and Lifetime Version: Boston: Behavioral Science Division, Boston VA Medical Center/Neurosciences Division, West Haven VA Medical Center.

Bonne, O., Vythilingam, M., Inagaki, M., Wood, S., Neumeister, A., Nugent, A.C., et al. (2008). Reduced posterior hippocampal volume in posttraumatic stress disorder. Journal of Clinical Psychiatry, 69(7), 1087-1091.

Bossini, L., Tavanti, M., Calossi, S., Lombardelli, A., Polizzotto, N.R., Galli, R., et al. (2008). Magnetic resonance imaging volumes of the hippocampus in drug-naive patients with post-traumatic stress disorder without comorbidity conditions. Journal of Psychiatric Research, 42(9), 752-762.

Brandt, J. (1991). The Hopkins Verbal Learning Test: Development of a new memory test with six equivalent forms. Clinical Neuropsychology, 5, 125-142.

Bremner, J.D., Randall, P., Scott, T.M., Bronen, R.A., Seibyl, J.P., Southwick, S.M., et al. (1995). MRI-based measurement of hippocampal volume in patients with combat- related posttraumatic stress disorder. American Journal of Psychiatry, 152(7), 973981.

Bremner, J.D., Randall, P., Vermetten, E., Staib, L., Bronen, R.A., Mazure, C., et al. (1997). Magnetic resonance imaging-based measurement of hippocampal volume in posttraumatic stress disorder related to childhood physical and sexual abuse-a preliminary report. Biological Psychiatry, 41(1), 23-32.

Bremner, J.D., Vythilingam, M., Vermetten, E., Southwick, S.M., McGlashan, T., Nazeer, A., et al. (2003). MRI and PET study of deficits in hippocampal structure and function in women with childhood sexual abuse and posttraumatic stress disorder. American Journal of Psychiatry, 160(5), 924-932.

Brewin, C.R., Kleiner, J.S., Vasterling, J.J., \& Field, A.P. (2007). Memory for emotionally neutral information in posttraumatic stress disorder: A meta-analytic investigation. Journal of Abnormal Psychology, 116(3), 448-463.

Coburn-Litvak, P.S., Tata, D.A., Gorby, H.E., McCloskey, D.P., Richardson, G., \& Anderson, B.J. (2004). Chronic corticosterone affects brain weight, and mitochondrial, but not glial volume fraction in hippocampal area CA3. Neuroscience, 124(2), 429-438.

Convit, A., de Leon, M.J., Tarshish, C., De Santi, S., Kluger, A., Rusinek, H., \& George, A.E. (1995). Hippocampal volume losses in minimally impaired elderly. Lancet, 345(8944), 266.

Dale, A.M., Fischl, B., \& Sereno, M.I. (1999). Cortical surfacebased analysis. I. Segmentation and surface reconstruction. Neuroimage, 9(2), 179-194.

Desikan, R.S., Segonne, F., Fischl, B., Quinn, B.T., Dickerson, B.C., Blacker, D., et al. (2006). An automated labeling system for subdividing the human cerebral cortex on MRI scans into gyral based regions of interest. Neuroimage, 31(3), 968-980.

First, M.B., Spitzer, M.B., Gibbon, M., \& Williams, J.B.W. (1995). Structured clinical interview for DSM-IV axis II personality disorders - patient (SCID-I/P), Version 2.0. New York: New York State Psychiatric Institute.

Fischl, B., \& Dale, A.M. (2000). Measuring the thickness of the human cerebral cortex from magnetic resonance images. Proceedings of the National Academy of Science of the USA, 97(20), 11050-11055.

Fischl, B., Sereno, M.I., \& Dale, A.M. (1999). Cortical surfacebased analysis. II: Inflation, flattening, and a surface-based coordinate system. Neuroimage, 9(2), 195-207.

Fischl, B., Sereno, M.I., Tootell, R.B., \& Dale, A.M. (1999). Highresolution intersubject averaging and a coordinate system for the cortical surface. Human Brain Mapping, 8(4), 272-284.

Fischl, B., van der Kouwe, A., Destrieux, C., Halgren, E., Segonne, F., Salat, D.H., et al. (2004). Automatically parcellating the human cerebral cortex. Cerebral Cortex, 14(1), 11-22.

Fortin, M., Voss, P., Lord, C., Lassonde, M., Pruessner, J., Saint-Amour, D., et al. (2008). Wayfinding in the blind: Larger hippocampal volume and supranormal spatial navigation. Brain, 131(Pt. 11), 2995-3005.

Gilbertson, M.W., Williston, S.K., Paulus, L.A., Lasko, N.B., Gurvits, T.V., Shenton, M.E., et al. (2007). Configural cue performance in identical twins discordant for posttraumatic stress disorder: Theoretical implications for the role of hippocampal function. Biological Psychiatry, 62(5), 513-520.

Golier, J.A., Harvey, P.D., Legge, J., \& Yehuda, R. (2006). Memory performance in older trauma survivors: Implications for the longitudinal course of PTSD. Annals of the New York Academy of Science, 1071, 54-66.

Gould, E., \& Tanapat, P. (1999). Stress and hippocampal neurogenesis. Biological Psychiatry, 46(11), 1472-1479.

Gurvits, T.V., Shenton, M.E., Hokama, H., Ohta, H., Lasko, N.B., Gilbertson, M.W., et al. (1996). Magnetic resonance imaging study of hippocampal volume in chronic, combat-related posttraumatic stress disorder. Biological Psychiatry, 40(11), 1091-1099.

Han, X., Jovicich, J., Salat, D., van der Kouwe, A., Quinn, B., Czanner, S., et al. (2006). Reliability of MRI-derived measurements of human cerebral cortical thickness: The effects of field strength, scanner upgrade and manufacturer. Neuroimage, 32(1), 180-194.

Harris, G.J., Jaffin, S.K., Hodge, S.M., Kennedy, D., Caviness, V.S., Marinkovic, K., et al. (2008). Frontal white matter and cingulum diffusion tensor imaging deficits in alcoholism. Alcohol Clinical Experimental Research, 32(6), 1001-1013.

Karl, A., Schaefer, M., Malta, L.S., Dorfel, D., Rohleder, N., \& Werner, A. (2006). A meta-analysis of structural brain abnormalities in PTSD. Neuroscience and Biobehavior Review, 30(7), 1004-031. 
Kates, W.R., Abrams, M.T., Kaufmann, W.E., Breiter, S.N., \& Reiss, A.L. (1997). Reliability and validity of MRI measurement of the amygdala and hippocampus in children with fragile $\mathrm{X}$ syndrome. Psychiatry Research, 75(1), 31-48.

Keane, T.M., Caddell, J.M., \& Taylor, K.L. (1988). Mississippi Scale for Combat-Related Posttraumatic Stress Disorder: Three studies in reliability and validity. Journal of Consulting and Clinical Psychology, 56(1), 85-90.

Keane, T.M., Fairbank, J.A., Caddell, J.M., Zimering, R.T., Taylor, K.L., \& Mora, C.A. (1989). Clinical evaluation of a measure to assess combat exposure. Psychological Assessment, 1(1), 53-55.

Kirschbaum, C., Wolf, O.T., May, M., Wippich, W., \& Hellhammer, D.H. (1996). Stress- and treatment-induced elevations of cortisol levels associated with impaired declarative memory in healthy adults. Life Sciences, 58(17), 1475-1483.

Laakso, M.P., Soininen, H., Partanen, K., Helkala, E.L., Hartikainen, P., Vainio, P., et al. (1995). Volumes of hippocampus, amygdala and frontal lobes in the MRI-based diagnosis of early Alzheimer's disease: Correlation with memory functions. Journal of Neural Transmission, Parkinson's Disease and Dementia Section, 9(1), 73-86.

Lang, S., Kroll, A., Lipinski, S.J., Wessa, M., Ridder, S., Christmann, C., et al. (2009). Context conditioning and extinction in humans: Differential contribution of the hippocampus, amygdala and prefrontal cortex. European Journal of Neuroscience, 29(4), 823-832.

Marquis, S., Moore, M.M., Howieson, D.B., Sexton, G., Payami, H., Kaye, J.A., \& Camicioli, R. (2002). Independent predictors of cognitive decline in healthy elderly persons. Archives of Neurology, 59(4), 601-606.

McEwen, B.S., \& Magarinos, A.M. (1997). Stress effects on morphology and function of the hippocampus. Annals of the New York Academy of Science, 821, 271-284.

McNally, R.J. (1998). Experimental approaches to cognitive abnormality in posttraumatic stress disorder. Clinical Psychology Review, 18(8), 971-982.

Metzger, L.J., Orr, S.P., Lasko, N.B., McNally, R.J., \& Pitman, R.K. (1997). Seeking the source of emotional Stroop interference effects in PTSD: A study of P3s to traumatic words. Integrative Physiological and Behavioral Science, 32(1), 43-51.

Nakano, T., Wenner, M., Inagaki, M., Kugaya, A., Akechi, T., Matsuoka, Y., et al. (2002). Relationship between distressing cancerrelated recollections and hippocampal volume in cancer survivors. American Journal of Psychiatry, 159(12), 2087-2093.

Osterrieth, P.A. (1944). Le test de copie d'ude figure complex: Contribution a l'edtude de la perception et de la memoire. Archives de Psycholgie, 30, 286-340.

Pavic, L., Gregurek, R., Rados, M., Brkljacic, B., Brajkovic, L., Simetin-Pavic, I., et al. (2007). Smaller right hippocampus in war veterans with posttraumatic stress disorder. Psychiatry Research, 154(2), 191-198.

Pederson, C.L., Maurer, S.H., Kaminski, P.L., Zander, K.A., Peters, C.M., Stokes-Crowe, L.A., \& Osborn, R.E. (2004). Hippocampal volume and memory performance in a community-based sample of women with posttraumatic stress disorder secondary to child abuse. Journal of Traumatic Stress, 17(1), 37-40.

Psychological Corporation (1997). Wechsler Adult Intelligence Scale, Third Revision. San Antonio, TX: Harcourt Brace.

Reiss, A.L., Hennessey, J.G., Rubin, M., Beach, L., Abrams, M.T., Warsofsky, I.S., et al. (1998). Reliability and validity of an algorithm for fuzzy tissue segmentation of MRI. Journal of Computer Assisted Tomography, 22(3), 471-479.
Rey, A. (1941). L'examen psychologique dans les cas d'enchphalopathie traumatique. Archives de Psycholgie, 28, 286-340.

Samuelson, K.W., Neylan, T.C., Metzler, T.J., Lenoci, M., Rothlind, J., Henn-Haase, C., et al. (2006). Neuropsychological functioning in posttraumatic stress disorder and alcohol abuse. Neuropsychology, 20(6), 716-726.

Sapolsky, R.M. (2000). Glucocorticoids and hippocampal atrophy in neuropsychiatric disorders. Archives of General Psychiatry, 57(10), 925-935.

Selzer, M.L. (1971). The Michigan alcoholism screening test: The quest for a new diagnostic instrument. American Journal of Psychiatry, 127(12), 1653-1658.

Shin, L.M., Shin, P.S., Heckers, S., Krangel, T.S., Macklin, M.L., Orr, S.P., et al. (2004). Hippocampal function in posttraumatic stress disorder. Hippocampus, 14(3), 292-300.

Simic, G., Kostovic, I., Winblad, B., \& Bogdanovic, N. (1997). Volume and number of neurons of the human hippocampal formation in normal aging and Alzheimer's disease. Journal of Comparative Neurology, 379(4), 482-494.

Soininen, H.S., Partanen, K., Pitkanen, A., Vainio, P., Hanninen, T., Hallikainen, M., et al. (1994). Volumetric MRI analysis of the amygdala and the hippocampus in subjects with age-associated memory impairment: Correlation to visual and verbal memory. Neurology, 44(9), 1660-1668.

Spreen, O., \& Strauss, E. (1991). A compendium of neuropsychological tests: Administration, norms and commentary. New York: Oxford University Press.

Stein, M.B., Koverola, C., Hanna, C., Torchia, M.G., \& McClarty, B. (1997). Hippocampal volume in women victimized by childhood sexual abuse. Psychological Medicine, 27(4), 951-959.

Talairach, J., \& Tournoux, P. (1988). Co-planar stereotaxic atlas of the human brain. New York: Thieme Medical.

Tata, D.A., Marciano, V.A., \& Anderson, B.J. (2006). Synapse loss from chronically elevated glucocorticoids: Relationship to neuropil volume and cell number in hippocampal area CA3. Journal of Comparative Neurology, 498(3), 363-374.

Tischler, L., Brand, S.R., Stavitsky, K., Labinsky, E., Newmark, R., Grossman, R., et al. (2006). The relationship between hippocampal volume and declarative memory in a population of combat veterans with and without PTSD. Annals of the New York Academy of Science, 1071, 405-409.

Vasterling, J.J., Proctor, S.P., Amoroso, P., Kane, R., Heeren, T., \& White, R.F. (2006). Neuropsychological outcomes of army personnel following deployment to the Iraq war. JAMA, 296(5), 519-529.

Vythilingam, M., Blair, K.S., McCaffrey, D., Scaramozza, M., Jones, M., Nakic, M., et al. (2007). Biased emotional attention in post-traumatic stress disorder: A help as well as a hindrance? Psychological Medicine, 37(10), 1445-1455.

Vythilingam, M., Luckenbaugh, D.A., Lam, T., Morgan, C.A.3rd, Lipschitz, D.,, Charney, D.S., et al. (2005). Smaller head of the hippocampus in Gulf War-related posttraumatic stress disorder. Psychiatry Research, 139(2), 89-99.

Wais, P.E. (2008). fMRI signals associated with memory strength in the medial temporal lobes: A meta-analysis. Neuropsychologia.

Wechsler, D. (1997). Wechsler Memory Scale-Third Edition: Administration and scoring manual. San Antonio, TX: The Psychological Corporation.

Woodward, S.H., Kaloupek, D.G., Streeter, C.C., Kimble, M.O., Reiss, A.L., Eliez, S., et al. (2007). Brain, skull, and CSF 
volumes in adult posttraumatic stress disorder. Journal of Traumatic Stress, 20, 763-774.

Woodward, S.H., Kaloupek, D.G., Streeter, C.C., Kimble, M.O., Reiss, A.L., Eliez, S., et al. (2006a). Hippocampal volume, PTSD, and alcoholism in combat veterans. American Journal of Psychiatry, 163(4), 674-681.

Woodward, S.H., Kaloupek, D.G., Streeter, C.C., Martinez, C., Schaer, M., \& Eliez, S. (2006b). Decreased anterior cingulate volume in combat-related PTSD. Biological Psychiatry, 59(7), $582-587$.

Woodward, S.H., Schaer, M., Kaloupek, D.G., Cediel, L., \& Eliez, S. (in press). Cerebral cortical volume is globally and regionally smaller in combat-related posttraumatic stress disorder. Archives of General Psychiatry.
Yehuda, R., Golier, J.A., Tischler, L., Harvey, P.D., Newmark, R., Yang, R.K., \& Buchsbaum, M.S. (2007). Hippocampal volume in aging combat veterans with and without post-traumatic stress disorder: Relation to risk and resilience factors. Journal of Psychiatric Research, 41(5), 435-445.

Yehuda, R., Golier, J.A., Tischler, L., Stavitsky, K., \& Harvey, P.D. (2005). Learning and memory in aging combat veterans with PTSD. Journal of Clinical Experimental Neuropsychology, 27(4), 504-515.

Zimmerman, M.E., Pan, J.W., Hetherington, H.P., Katz, M.J., Verghese, J., Buschke, H., Derby, C.A., \& Lipton, R.B. (2008). Hippocampal neurochemistry, neuromorphometry, and verbal memory in nondemented older adults. Neurology, 70(18), $1594-1600$. 